\title{
THE ROCKET SCIENCE: READING FINANCIAL ACCOUNTING STANDARDS
}

\author{
Brian Farrell \\ University of Technology, Sydney \\ Helen Farrell \\ University of New South Wales \\ and \\ Peter Wells \\ University of Technology, Sydney
}

\begin{abstract}
$\mathrm{T}$

his paper identifies readability as a significant obstacle to the international

harmonisation of financial accounting standards. In the study, the Flesch Reading Ease and the Flesch-Kincaid Grade Level tests are used to analyse the International Financial Reporting Standard on leases (using the Australian equivalent, $A A S B$ 117), the other international standards (using the remaining 46 AASB standards), and the US standard on leases, FAS 13. The results show the language of AASB 117 and FAS 13 exceeds the expected ability of many readers and represents an impediment to the interpretation of accounting standards. T-tests indicate that, on average, the Reading Ease and Grade Level scores of the other 46 AASB standards are significantly more demanding than even AASB 117. Consequently, the readability of the International Financial Reporting Standards ought to be comprehensively addressed by the International Accounting Standards Board to ensure the efficacy of efforts to harmonise accounting internationally.
\end{abstract}

Frankly, accounting is not rocket science.

(Tweedie, 2007, p. 5) 
Farrell, Farrell and Wells

\section{INTRODUCTION}

Doubtless the greatest change to have occurred internationally in financial reporting in recent years has been the adoption of International Financial Reporting Standards (IFRS) in many countries, including Ireland. Australia is typical and, since 2005, firms have been required to use the Australian equivalent of the IFRS, known as the Australian Accounting Standards Board (AASB) standards. Numerous motivations have been identified by regulators in support of this regulatory change, including improvements in the quality of financial reports, broader access to international capital markets and lower cost of capital for firms (see, for example, Financial Reporting Council, 2002). Reflecting the significance of these changes, researchers have expended considerable effort to determine whether these benefits are being delivered (Barth, Landsman and Lang, 2008; Barth, Landsman, Lang and Williams, 2007; Armstrong, Barth, Jagolinzer and Riedl, 2007). However, the existence of the accounting standards alone is not sufficient to achieve these benefits, and little attention has been directed towards other factors which influence whether the benefits associated with them are realised. This includes the ability of accounting professionals and students to understand and apply the accounting standards.

A feature of the accounting standards developed by the International Accounting Standards Board (IASB) is the complexity of their language and concepts. While this may be seen by some as necessary to deliver precision and to ensure that financial reports capture the underlying economic substance of transactions, a consequence is that readability may be sacrificed. Accordingly, the major objective of this study is to evaluate whether the readability level of the language used in accounting standards constitutes an impediment to the financial accounting harmonisation project. This is of concern for practitioners, auditors and regulators, and academics training accounting professionals.

A secondary objective of this paper is to compare the readability of lease standards issued in the United States (US) by the Financial Accounting Standards Board (FASB) and the IASB. This is relevant for a number of reasons. Firstly, these standards are written in a different style, and the comparison provides evidence as to whether style impacts the readability of the standards. Secondly, it may provide insights relevant to the present debate in the US surrounding regulatory change. In relation to the latter point, it is recognised that there are other perhaps more important issues, such as how different regulatory styles impact auditor judgement (see, for example, Nelson, Elliott and Tarpley, 2002). However, the issue of whether standards are easily read is not trivial.

\section{On Terminology}

At the outset, a threshold clarification of two terms used in this paper is relevant (Smith and Taffler, 1992). First, we use the term 'understandability' in this paper. This relates to the degree a reader can decode the language of a text so as to derive its meaning and 'receive the message' that is intended to be conveyed by the author. Understanding text depends on many factors. Some relate to the reader personally and are subjective. Such factors include intellectual ability, topic interest, education, attention span, eyesight health and shared knowledge with the author. Other 
factors are external to and independent of a reader, and may be considered 'objective'. These are items such as the available light illuminating the text, the size and style of font used, the colour of the print and the contrasting colour of the paper or screen on which the text appears. The language of the text, including its register (be it academic, conversational, legalistic or other), also falls within this category.

The second term to clarify is 'readability'. This is a quality of the text itself, and is independent of the characteristics and circumstances of an individual reader. It is objectively assessed. The readability quality as a generally understood term relates to the structure of the language and how easily it is managed by a reader. Readability contributes to the ability of the reader to decode the text in a process of ascertaining its meaning. Readability is one factor among many that contribute to an understanding of text by a particular reader. In a practical sense, it is not possible for a person to distinguish what they understand from exposure to a text from what they gain from its reading. The reading is linked to a level of understanding to which it contributes. Despite this, it is possible to measure the text itself based on aspects that determine the level of difficulty the text structure itself presents to the reader.

The remainder of this paper is organised as follows. The next section provides an overview of the institutional setting and literature review. Research design is addressed in the third section and the results are presented in the fourth section. In the final section, the conclusions are discussed.

\section{INSTITUTIONAL SETTING AND LITERATURE REVIEW}

The most significant innovation in financial reporting in recent years has been international harmonisation. This has typically occurred through countries aligning their financial reporting standards with the model set issued by the IASB (Heffes and Graziano, 2007; Callao, Jarne and Lainez, 2007; Cormier, Demaria, LapointeAntunes and Teller, 2009; Paananen and Lin, 2009). ${ }^{1}$ In developing standards, the IASB has faced a number of challenges, including an increasingly complex business environment and the need for precision in the standards. Doubtlessly, this contributed to the adoption of one language, English, as the authoritative text of the standards (International Accounting Standards Committee, 2007, article 32). Importantly, this avoids conflict in interpretation across various language versions, and limits the potential for alternative, official versions of the regulations that could undermine the quality of outcomes to be expected from harmonisation. ${ }^{2}$

However, the need for precision in the standards and the focus on English as the official language present problems. In fact, the issue of the language used in the standards has been raised in convergence and harmonisation discussions. Concerns have been expressed that the English of accounting narratives is not plain and simple (Courtis, 1998; Rutherford, 2003). The argument presented here is that an outcome of the increasing complexity is the lessening of the readability contribution to the understanding of the standards.

The English used in financial reporting has attracted the interest of accounting researchers and not only within English-speaking countries. Jeanjean, Lesage and 
Farrell, Farrell and Wells

Stolowy (2010) report that 50 per cent of their sample of 3,994 firms for 2003 (49 per cent of 3,844 firms for 2004) across 27 non-English-speaking countries issued English language annual reports. While focusing on the text of management discussion and analysis, Courtis (1998) notes that communication would be enhanced if regard was given to the reading and comprehension abilities of report users. Similarly, Rutherford (2003) provides evidence of the language in financial reports for poorly performing companies being particularly complex. While this lack of clarity cannot be attributed to obfuscation, the issue of whether financial reports are sufficiently readable remains. The same issues arise with respect to accounting standards, due to the way in which they dictate the content of financial reports. Critically, if preparers and users have difficulties reading the text of standards, the quality of those reports will be indirectly undermined. Furthermore, the language requirement of financial reporting standards is clearly articulated by Sir David Tweedie, chairman of the IASB, who expressed the view that:

...a good principles-based standard must pass four tests:

i. Is the standard written in plain English? ...

ii. Can the standard be explained simply in a matter of a minute or so?

iii. Does it make intuitive sense?

iv. Does management believe it helps them to understand and describe the underlying economic activity?

(Tweedie, 2007, p. 5)

The problem of developing accounting regulations is not unique to the IASB. In the US, the $\mathrm{FASB}^{3}$ faces a similar challenge, and it is noteworthy that over the last few years these two organisations have increasingly cooperated and sought to minimise differences in accounting practices (see, for example, the Norwalk Agreement (Financial Accounting Standards Board and the International Accounting Standards Board, 2002)). However, there remain apparently significant differences in the written style of accounting standards. In contrast to the standards developed by the IASB, which are typically described as 'principles-based', the standards developed by the FASB are commonly labelled 'rules-based' (for a discussion, see, for example, Benston, Bromwich and Wagenhofer, 2006). Critics of the FASB regulations allege that this approach fosters a 'check box' or compliance mentality, and that this contributed to financial reporting crises in the US (Schipper, 2003). Furthermore, there have been calls to adopt a principles-based approach to standard setting in the US (MacDonald, 2002). Whether this should occur has been the subject of discussion (see, for example, Maines, Battov, Fairfield, Hirst, Iannaconi, Mallett, Schrand, Skinner and Vincent, 2003), and has brought into question the appropriateness of the labels typically applied to the regulatory styles. For example, it is difficult to argue that the standards developed by the FASB are not based upon principles, captured for instance in the conceptual framework statements. The requirements of these principles are expressed as objective statements which look like rules. The IASB is developing standards based upon essentially the same principles. However, these are expressed as subjective statements. The behavioural implications 
of this different regulatory style (objective versus subjective statements) have been considered (Nelson, 2003), but not the impact on the readability of the standards.

\section{Readability}

As this paper is concerned with the readability of the standards developed by the accounting community, the focus is necessarily on external factors independent of the reader. 'Readability' is one element that contributes towards understanding text, but is itself a somewhat nebulous concept and so this paper provides a range of predictions of the readability of accounting standards. It should be noted that the objective tests used in this study are predictions related to the characteristics of the text alone. They provide indications of whether the text may be difficult to 'handle'. The tests do not predict the complexity of the subject matter nor whether a particular reader is able to grasp the meaning intended by the author. The indicators of readability used in the analysis are the Flesch Reading Ease Index, the FleschKincaid Grade Level Index, and Lexical Density and Grammatical Intricacy from Functional Grammar.

\section{Flesch Reading Ease Index}

Many of the original, non-grammatical tests of readability were based on mathematical formulae, and this continues today for most tests (see McLellan and Dobinson, 2004 for a brief survey of several tests). Other methods involve objective questionand-answer techniques, tables and charts, and sentence completion. For example, the Cloze Procedure is a sentence completion method. It requires a person to recall and supply every fifth word in a passage which has been previously read without words missing (Gilliland, 1972). In this way the text is judged as having a particular level of readability depending on the age of the tested reader. However, some researchers (e.g. Woods, Moscardo and Greenwood, 1998) regard the Cloze Procedure to be more related to comprehension than to readability, and thus not relevant here.

Formulae tests that have received support and usage over the years include the Fog Index designed by Gunning (1952), which is based on counts of words, sentences and complex words; the Dale and Chall approach (1948), in which a count is made of words outside a list of 3,000 commonly used words; and the Simple Measure of Gobbledegook (SMOG) (McLellan and Dobinson, 2004), based on adding three to the square root of a polysyllable count. Indeed, there are many tests available, suggested to be about 200, with some of them listed in Woods et al. (1998) and DuBay (2004). However, Zakaluk and Samuels (1988, p. 117) conclude that:

... classic readability formulas ... are intended to and do predict an approximate level of difficulty. Critics would like these formulas to account for more of the complexities of text. Readability research has shown that the addition of attributes does not increase the reliability of the formulas.

The Flesch Reading Ease Index was selected as representative of these formulaebased methods since it is accepted as a 'highly reliable measure' of literature for adults (Rogers, Harrison, Shuman, Sewell and Hazlewood, 2007). Devised in 1948, it is based on a formula relating readability to sentence length expressed in words 
Farrell, Farrell and Wells

and the syllable count per 100 words (Flesch, 1950). The higher the score achieved in the analysis of a text, the better the readability. The formula for the Flesch Reading Ease Index (FREI) is:

$$
F R E I=206.835-1.015 A S L-84.6 A S W
$$

where ASW represents the average number of syllables per word, while ASL is the average sentence length. Literature on the FREI suggests that a score around 90-100 means the text can be easily read by fifth graders (US education system), who are typically 10 to 11 years old. A score around 60-70 can be handled by eighth and ninth graders while scores below 30 are managed by university graduates. This is reflected in Table 1, which relates index scores to readability.

TABLE I: FLESCH READING EASE INDEX (FREI)

\begin{tabular}{lc}
\hline \multicolumn{1}{c}{ Score } & Interpretation \\
\hline $0-30$ & Very difficult \\
$30-50$ & Difficult \\
$50-60$ & Fairly difficult \\
$60-70$ & Normal \\
$70-80$ & Fairly easy \\
$80-90$ & Easy \\
$90-100$ & Very easy \\
\hline
\end{tabular}

Source: Flesch, 1950, p. 388.

\section{Flesch-Kincaid Grade Level Index}

Closely related to the Flesch Reading Ease Index is the Flesch-Kincaid Grade Level Index (FKGLI), which is based on the same language variables, but the results are expressed as a grade level (US education system) required for readability. Its development was commissioned by the US Navy in 1976 and, importantly, a validation process was included in the project (DuBay, 2004). The outcome of the study was the Flesch-Kincaid Grade Level Index. It is calculated according to the following formula:

$$
F K G L I=0.39 A S L+11.8 A S W-15.59
$$

where, as in the previous formula, ASW represents the average number of syllables per word and $A S L$ is the average sentence length.

Both the Flesch Reading Ease Index and the Flesch-Kincaid Grade Level Index have been used extensively in diverse contexts. Examples include the readability of health materials and, in particular, directions for contraceptive use (WilliamsDeane and Potter, 1992), health promotions (Harvey and Fleming, 2003), diabetes information (Kerr, 2007), hospital discharge forms (Fung, Willer, Moreland and Leddy, 2006), and nutrition websites (Stalebrink and Sacco, 2007). The tests have 
also been employed in studies on newspapers (McLellan and Dobinson, 2004), privacy notices (Fung et al., 2006), Miranda warnings ${ }^{4}$ (Rogers et al., 2007), agricultural contracts (Goodhue and Hoffmann, 2006), tax rulings (Wallis, 2005), political science textbooks (Heilke, Joslyn and Aguado, 2003), psychology reports (Harvey, 2006) and the Australian Goods and Services Tax Act (Richardson and Smith, 2002). In the accounting discipline, numerous analyses of readability using these tests have been undertaken in such areas as annual reports (Beattie, McInnes and Fearnley, 2004; Clatworthy and Jones, 2001), accounting disclosure in corporate governance (Rutherford, 2003), auditors' suggestion letters (Hagge and Kostelnick, 1989) and accounting narratives (Sydserff and Weetman, 1999). The tests have also been used by Davidson (2005) to analyse the readability of accounting textbooks published over a 100 -year period.

In summary, there is ample evidence of these tests being used widely. ${ }^{5}$ Moreover, the nature of the measures is consistent with the objectives of this paper, being the evaluation of the language of regulations against the benchmark of 'plain and simple' set by Tweedie (2007). Contrary to the views of some critics, both tests were designed to evaluate texts for adults and were validated using adult readers (Stockmeyer, 2009).

\section{RESEARCH DESIGN}

\section{Regulatory Context}

An initial concern with this study was determining the specific standards to evaluate. The issue of leases was identified and the regulations AASB 117 Leases (the Australian equivalent of International Accounting Standard (IAS) 17 Leases) and Financial Accounting Standard (FAS) 13 Accounting for Leases (both versions as at 2007) were selected for a number of reasons. Firstly, for comparability the standards must address a common issue, and their scope limited to that issue. Secondly, the standards needed to be a clear demonstration of the different regulatory styles. Thirdly, the issue is non-trivial and the accounting alternatives have been widely canvassed. Finally, there is broad agreement about appropriate accounting practices. ${ }^{6}$ AASB 117 Leases was chosen rather than IAS 17 Leases, as it is consistent with the international standard and addresses a potential criticism that the analysis in this paper is not of an accounting standard as applied in practice.

While the focus on one accounting area is a limitation of this study, the results from $t$-tests on non-grammatical readability scores on all the AASB standards other than AASB 117 indicate that on average the latter is significantly easier to read than the other 46 AASB standards (see results section below).

The Flesch Reading Ease and Flesch-Kincaid Grade Level tests were applied to each standard as one text, and also to paragraphs separately. ${ }^{7}$ The latter provided an insight into the range of reading ease and grade level indices which might otherwise be lost if the only scores taken were of the full text as one piece of literature. The readability of individual passages of each standard analysed was calculated, omitting tables, headings, illustrations and lists of contents, to ensure a focus on the core content. Other than a two-page Implementation Guide, there was no 
Farrell, Farrell and Wells

additional material annexed to AASB 117, but such was not the case for FAS 13. For that standard of 84 pages, 57 contained annexures and schedules to the standard. Only the standard itself was included in the analysis as this was considered sufficient to assess for readability.

Both the above methods require a definition of a sentence. For the purpose of these tests, sentences were defined by the use of a 'full stop' (US 'period') punctuation mark rather than the presence of a finite verb, which is sometimes applied. A consequence of this is that in the US standard where paragraphs consisted of a stem and several branches and there was a full stop at the end of each branch, the stem and the first branch was counted as one sentence and all the subsequent branches as separate sentences. In comparison, for the Australian standard the end of each branch had a semi-colon so that the stem and all branches constituted just one sentence. While the difference in punctuation caused a difference in scores, the number of such cases was small and adjustment was not considered necessary. All headings, whether with or without a following full stop, were not counted.

A simple word count per sentence of a text is also commonly used in conjunction with the above indices. While this is a relatively naïve measure of readability, it can highlight significant differences across regulations, and so a word count was also undertaken.

\section{Systemic Functional Grammar}

A potential criticism of the above tests is that they focus quite mechanistically on the number of syllables and length of sentences. While this is well suited to the evaluation of significant volumes of text, a more detailed analysis is possible through techniques available from Systemic Functional Grammar and using samples of the texts. Systemic Functional Grammar is a recognised methodology for textual analysis. ${ }^{8}$

One method of analysing texts available from Systemic Functional Grammar is Lexical Density, which focuses on the words used in sentences. The extensive use of 'content' words may contribute to Lexical Density, and this may be evaluated by 'expressing the number of content carrying words in a text/sentence as a proportion of all the words in the text/sentence' (Eggins, 2004, p. 97). The higher the proportion of content words the higher the Lexical Density, and the more difficult it is to read and understand the text (see, for example, Halliday, 1994; Martin, 1992; Eggins, 2004). Other factors contribute to Lexical Density, including the compression of words into clauses or phrases. A simple example of this would be the reduction of 'term of the lease' to 'lease term'. A more detailed explanation of the application of this technique is deferred to the results section where it is related to the text being analysed.

Another linguistic indicator for analysing texts is Grammatical Intricacy. This focuses more on the sentence structure, and is assessed on the basis of sentence clauses and themes (Eggins, 2004). In the first instance, Grammatical Intricacy is 'calculated by expressing the number of clauses in a text as a proportion of the number of sentences in the text' (Eggins, 2004, p. 97). The argument is not that all sentences in technical texts should ideally be composed of few clauses per sentence. Often, to express a complex idea the writer needs to construct a complex sentence 
composed of several clauses in order to do justice to the complexity of thought. However, when complex grammatical sentences are combined with high Lexical Density, the texts may become inaccessible for many readers (Eggins, 2004). Other factors impacting Grammatical Intricacy include the themes of clauses. Again, a more detailed explanation is deferred to the results section where it is related to the text being analysed.

As the techniques of Systemic Functional Grammar involve the detailed analysis of text it was not feasible to apply it to the text of an entire standard. In this research, the techniques were applied to samples of text chosen at random from positions one-, two- and three-quarters of the way through each of the accounting standards.

\section{RESULTS AND DISCUSSION}

This section contains the results and discussion of the Readability Ease and Grade Level scores for AASB 117 and FAS 13. It should be noted that some of the paragraphs analysed have less than 100 words. The validation and early use of the Readability Ease and Grade Level tests were with sample passages of 100 words, and so the results for paragraphs of less than 100 words are outside the validation testing of the indices. The section concludes with findings from the analysis of AASB 117 using Lexical Density and Grammatical Intricacy from Systemic Functional Grammar.

\section{Flesch Readability Ease Index}

Attention is directed in the first instance towards the results from the estimation of the Flesch Readability Ease Index (FREI). For AASB 117, when evaluated as a single text, the score was 30.5, which suggests that the standard was 'difficult', bordering on 'very difficult', to read. When the paragraphs were evaluated separately, the mean (median) paragraph score was 29.6 (29.2), which was consistent with the result when the standard was evaluated as a single text. However, it was apparent that there is considerable variation across paragraphs, with a minimum score of $0^{9}$ and a maximum score of 53.4. Given that a score below 30 is indicative of 'very difficult' to read text, this suggested that the readability of the text was generally poor. This is highlighted in Figure 1, which shows that 52 per cent of the paragraphs had scores below 30 and were 'very difficult' to read, while less that 6 per cent of paragraphs had scores above 50 and were at best 'fairly difficult' to read.

The evidence clearly suggested that AASB 117 did not rate well for readability by this measure.

For comparative purposes, FAS 13 was also evaluated. For the entire text the score was 31.9, which is a slight improvement on AASB 117, although this was still near the top end of the 'difficult' range. For the analysis by paragraph, the mean (median) paragraph score was $28.4(30.8)$, with a minimum of $0^{10}$ and a maximum of 57.2, which was consistent with the results for AASB 117. The results are summarised in Figure 2, which shows that 47 per cent of paragraphs had a score below 30 and would be considered 'very difficult' to read. There were marginally more paragraphs ( 7 per cent) with a score of more than 50 , which would be considered at best 'fairly difficult' to read. 
Farrell, Farrell and Wells

FIGURE I: AASB II 7 READABILITY EASE BY PARAGRAPH $(\mathbf{N}=68)$

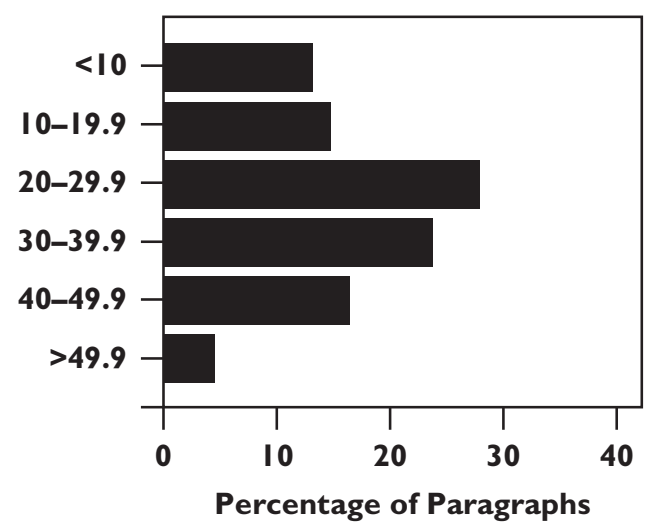

Accordingly, the results for the FREI suggested that while FAS 13 was marginally more readable than AASB 117, both had non-trivial readability problems.

FIGURE 2: FAS I3 READABILITY EASE BY PARAGRAPH $(\mathbf{N}=5 \mathrm{I})$

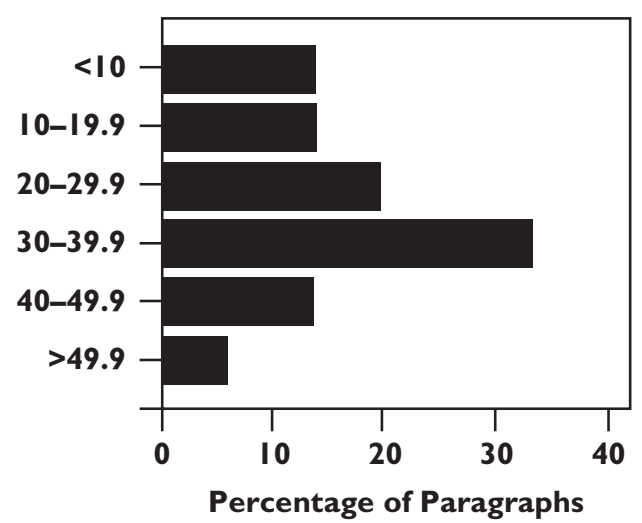

Flesch-Kincaid Grade Level Index

An alternative readability measure is the Flesch-Kincaid Grade Level Index (FKGLI), which expresses readability in terms of the education required to read the text, and the results are broadly consistent with those reported above.

When evaluated as one single text, AASB 117 achieved a FKGLI score of 15.4. Consistent with this, when paragraphs were evaluated separately the mean (median) score was 16.2 (15.5), with a minimum of 9.2 and a maximum of 24.8. The results are summarised in Figure 3, indicating somewhat problematically that 14.7 per cent of the paragraphs required a notional educational grade of 20 or more. This contrasts with grade 12, the highest grade in the US school education system. 
FIGURE 3: AASB II 7 GRADE LEVEL BY PARAGRAPH $(\mathbf{N}=68)$

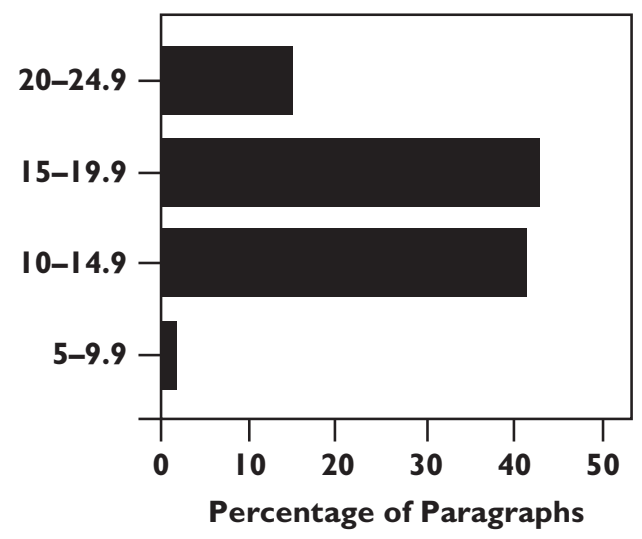

In comparison, when FAS 13 was evaluated as a single text, the FKGLI score was 16.3. When individual paragraphs were evaluated, their mean (median) score was 17.2 (16.4), and the paragraph scores ranged from 10.1 to 30.9. The results are summarised in Figure 4. Again, it is problematic that 27.5 per cent of the paragraphs required an education in excess of a notional grade of 20.

Thus, while there was evidence that more paragraphs in FAS 13 have extremely high FKGLI scores when compared to AASB 117, it cannot be argued that either standard rated well with this readability measure.

Grade level scores as high as those reported above are problematic. They could be regarded as artificial for the lack of a degree, course or educational process requiring 30 years of education. That view is not rejected here. However, the position is taken that, even if the measure is a 'phantom' grade, it does clearly indicate the level of difficulty the paragraphs present to a reader, even with a university education of around four years. In this context, where there are relatively numerous paragraphs

FIGURE 4: FAS I 3 GRADE LEVEL BY PARAGRAPH $(\mathbf{N}=5 \mathrm{I})$

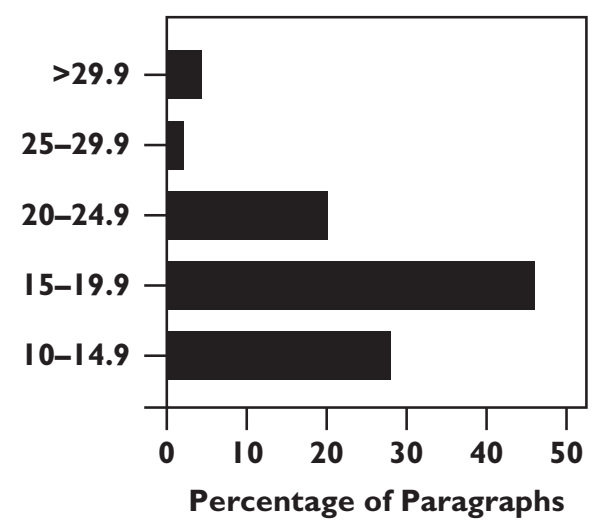


Farrell, Farrell and Wells

at or exceeding Grade 20, accounting students are required to comprehend and apply the standards early in their post-school education - at Grade 14 or 15.

\section{Word Count by Sentences}

Possibly contributing to the results above for readability is the length of the sentences. While not typically considered a measure of readability, it is recognised as having an impact on readability. Reflecting this, the number of words in the sentences of both standards was analysed. As a benchmark it should be noted that well-written sentences typically contain 30 to 40 words.

The mean (median) number of words per sentence for AASB 117 was 40 (32). Thirty-five per cent of the sentences in that standard had in excess of 40 words, six sentences exceeded 100 words, and the longest sentence had 191 words. A summary of the results is presented in Figure 5.

An analysis of FAS 13 produced a similar result. The mean (median) number of words per sentence was 37.9 (33), and a similar percentage (36 per cent) of sentences exceeded 40 words. Five sentences exceeded 100 words, with the longest having 154 words. Although the latter was slightly more modest than for AASB 117, it remains a worrying aspect with its likely impact on readability. Figure 6 provides a summary of the results.

Not captured in the above analysis were a number of factors relevant to the determination of readability. Firstly, it was striking that FAS $13^{11}$ contained 11,632 words, compared to 6,035 words in AASB $117 .{ }^{12}$ Interestingly, the length of the texts did not impact the readability measures reported above, either positively or negatively. Secondly, the extensive number of words per sentence was consistent with the predominant linguistic register being legalistic. This is a recognised problem in the legal fraternity. Long sentences traditionally used in law have been the subject of extensive reform efforts to employ plain English in legal documents. ${ }^{13}$

As highlighted above, there was little difference in the readability test results for the 'principles-based' AASB 117 standard and the similar 'rules-based' FASB standard (if that distinction is maintained). From the nature of the tests used, which only

Figure 5: AASB I I 7 WORD COUNT BY SENTENCE $(\mathbf{N}=15 \mathrm{I})$

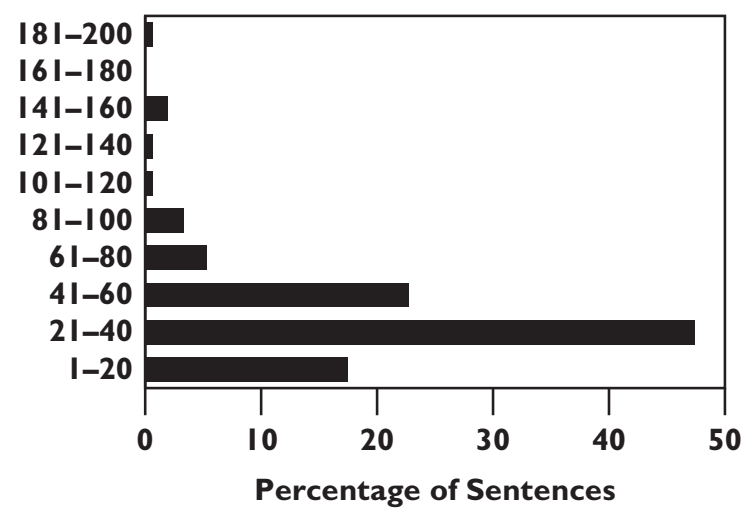


FIGURE 6: FAS I 3 WORD COUNT BY SENTENCE $(\mathbf{N}=\mathbf{2 7 4})$

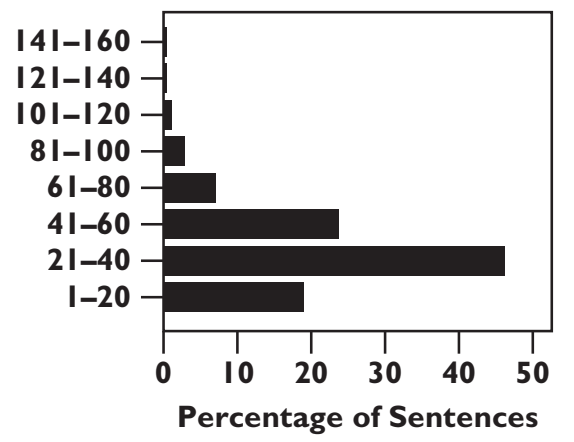

incorporated the number of words, sentences and syllables, the results were not unexpected. Both standards suffered from complexity and extensive length.

\section{The Representativeness of the Standard on Leases}

To determine whether the readability scores by paragraph obtained for AASB 117 were representative of the other 46 AASB standards, Readability Ease and Readability Grade Level scores were also ascertained for all other AASB standards. The results from $t$-tests on the scores by paragraph for the other 46 AASB standards indicate that AASB 117 is significantly easier to read $(\mathrm{p}<0.01)$ than all the others on average. The mean for Reading Ease of the 46 standards was 20.7, while it was only 29.6 for AASB 117. The Reading Grade mean was 17.5 for the 46 standards and 16.2 for AASB 117. Thus, the 46 standards pose an even greater challenge than reported in this paper for the standard on leases.

\section{Systemic Functional Grammar}

The above analysis is quite mechanical in its focus on words, sentences and paragraphs. Addressing this potential limitation, a Systemic Functional Grammar analysis was undertaken. Because of the extensive analytical work involved, the tests were based on a limited sample of three paragraphs from each standard. The analysed paragraphs are listed in Tables 2 and 3, with their Readability Indices (FREI and FKGLI) given to aid in the evaluation of the results.

TABLE 2: AASB II TTEXTS USED FORTEXTUAL ANALYSIS (WITH THEIR READABILITY INDICES)

\begin{tabular}{cccc}
\hline Paragraph Number & $\begin{array}{c}\text { Total Words in the } \\
\text { Paragraph }\end{array}$ & $\begin{array}{c}\text { Readability Ease } \\
\text { Index }\end{array}$ & Grade Level Index \\
\hline 16 & 104 & 10.8 & 24.6 \\
33 & 36 & 19.8 & 12.0 \\
50 & 41 & 16.6 & 21.1 \\
\hline
\end{tabular}


Farrell, Farrell and Wells

TABLE 3: FAS I 3 TEXTS USED FOR TEXTUAL ANALYSIS (WITHTHEIR READABILITY INDICES)

\begin{tabular}{cccc}
\hline Paragraph Number & $\begin{array}{c}\text { Total Words in the } \\
\text { Paragraph }\end{array}$ & $\begin{array}{c}\text { Readability Ease } \\
\text { Index }\end{array}$ & Grade Level Index \\
\hline 12 & 254 & 22.3 & 20.6 \\
24 & 44 & 19.8 & 21.4 \\
36 & 37 & 25.2 & 18.9 \\
\hline
\end{tabular}

Lexical Density was determined first, in particular the proportion of content words in a sentence. Content words include adjectives, nouns, some verbal forms and adverbs, while non-content words are typically articles (the, an, a), prepositions (e.g. on, in, under) and conjunctions (e.g. and, but, or). In the following extract from AASB 117 (para. 33), the content words are underlined:

...unless another systematic basis is representative of the time pattern of the user's benefit.

Similarly, the content words of the opening sentence of FAS 13 (para. 12) are underlined below:

During the lease term, each minimum lease payment shall be allocated between a reduction of the obligation and interest expense so as to produce a constant periodic rate of interest on the remaining balance of the obligation.

The results from the analysis of the sample paragraphs are presented in Table 4 . To provide a benchmark for evaluating these results, Eggins (2004) describes a written text with a score of 42 per cent as having a 'high Lexical Density'. These results suggest that both AASB 117 and FAS 13 have high Lexical Density, and while experienced accounting professionals may be able to cope with this, it is likely to be problematic for inexperienced readers of the standards, and in particular accounting students.

TABLE 4: CONTRASTING THE LEXICAL DENSITY OF THE SIX PARAGRAPHS ANALYSED

\begin{tabular}{lccccccc}
\hline & \multicolumn{3}{c}{ AASB I I7 } & \multicolumn{3}{c}{ FAS I3 } \\
\multicolumn{1}{c}{ Paragraphs } & $\mathbf{1 6}$ & $\mathbf{3 3}$ & $\mathbf{5 0}$ & $\mathbf{1 2}$ & $\mathbf{2 4}$ & $\mathbf{3 6}$ \\
\hline Number of content-carrying lexical items & 35 & 7 & 25 & 121 & 27 & 20 \\
Number of lexical items in paragraph & 72 & 14 & 40 & 256 & 47 & 37 \\
Total Lexical Density & $48 \%$ & $50 \%$ & $62.5 \%$ & $47 \%$ & $57 \%$ & $54 \%$ \\
\hline
\end{tabular}

The impact of Lexical Density may be mitigated when text has clear logical markers to guide the reader. For example, words such as 'next', 'furthermore', 'since' and 'consequently' provide the reader with identifiable cohesive links to assist with comprehension of the texts. However, these are not present in the text analysed. 
Instead, the reader of these standards is reliant only on headings and paragraph numbering for cohesion.

A number of factors exacerbate Lexical Density and these were noted during the course of the analysis. A significant proportion of the content words were technical words. Technical language is the language used within any profession and for the accounting profession includes 'purchase options', 'credit', 'debit' and 'fair value'. Examples of technical language used in the standards include 'amortization', 'residual guarantee' (FAS 13, para. 12), 'inception of the lease' (AASB 117, para. 16) and 'unless another systematic basis is more representative of ...' (AASB 117, para. 33).

Technical words form part of the professional jargon, but their combination with other linguistic patterns compounds Lexical Density. For instance, when verbs and adjectives are used as nouns (nominalised), the text becomes conceptually demanding for the reader. For example, 'depreciation' (AASB 117, para. 51), 'reduction', 'obligation', 'failure' and 'accordance' (FAS 13, para. 12), 'equipment' (FAS 13, para. 24) and 'agreement' (FAS 13, para. 36) are all examples of nominalisations. The following text has multiple examples of both technical language (underlined) and nominalisations (italics) occurring in the same sentence:

In the event that ...the asset and the obligation under the lease shall be adjusted by an amount equal to the difference between the present value of the future minimum lease payments under the revised agreement and the present balance of the obligation (FAS 13, para. 12).

In the following example, technical language and nominalisations overlap. In addition, the reader is required to recall information from other sections of the text.

In accordance with paragraph 9, other renewals and extensions of the lease term shall be considered new agreements, which shall be accounted for in accordance with the provisions of paragraph 14 (FAS 13, para. 12).

The compression of clauses or phrases contributes further to Lexical Density. For instance, the noun groups 'the lease term' and 'lease payment' in 'During the lease term, each minimum lease payment shall be allocated ...' (FAS 13, para.12) are reductions of the phrases 'the term of the lease', and 'payment of the lease'. Similarly, the texts from AASB 117 exhibit the same patterns: 'the minimum lease payments ... are allocated between the land and the buildings elements in proportion to ...' (AASB 117, para. 16). The noun groups underlined in the last example are interesting since not only are meanings condensed, but an additional sophisticated usage occurs. 'Land and buildings', which are usually used as nouns, are used here as descriptive words (adjectives).

Finally, the following sentence has a very high Lexical Density due to a combination of compressed phrases or clauses (bold), technical terms (underlined) and nominalisations (italics). This combination of linguistic features would require from most accounting professionals and experienced readers much effort to unpack:

Lease income from operating leases shall be recognised in income on a straight line

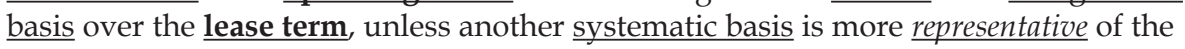
time pattern of the user's benefit (AASB 117, para. 33). 
Farrell, Farrell and Wells

It is clear to the reader of these examples that the purpose of the writers is to achieve textual brevity, and in most instances the examples provided appear to be innocuous enough. However, when this usage occurs persistently throughout a text, the reader can be lost in the abstractions.

A further indicator of readability in Systemic Functional Grammar is Grammatical Intricacy. This is measured in the first instance as 'the number of clauses in a text as a proportion of the number of sentences in the text' (Eggins, 2004, p. 97). It should be noted that scores above 2.6 have been identified as high (Eggins, 2004); the results from the analysis of the sample texts are presented in Table 5.

TABLE 5: CONTRASTING THE GRAMMATICAL INTRICACY OF THE SIX PARAGRAPHS ANALYSED

\begin{tabular}{lccccccc}
\hline & \multicolumn{3}{c}{ AASB II7 } & \multicolumn{3}{c}{ FAS I3 } \\
\multicolumn{1}{c}{ Paragraphs } & $\mathbf{1 6}$ & $\mathbf{3 3}$ & $\mathbf{5 0}$ & $\mathbf{1 2}$ & $\mathbf{2 4}$ & $\mathbf{3 6}$ \\
\hline Number of clauses in the text & 6 & 2 & 3 & 13 & 5 & 2 \\
Number of sentences in the text & 2 & 1 & 1 & 6 & 1 & 1 \\
Grammatical Intricacy Score & 3.0 & 2.0 & 3.0 & 2.1 & 5.0 & 2.0 \\
\hline
\end{tabular}

These results are not as problematic as those for Lexical Density, but still suggest that at least sections of both standards are grammatically intricate, which is unlikely to ameliorate the impacts of Lexical Density.

A number of factors exacerbate Grammatical Intricacy and these were noted during the course of the analysis. This includes the positioning of the theme of a sentence, which is typically at the beginning. However, it should be noted that there is considerable flexibility in English to accommodate a variety of themes as the starting point for the 'message'. Generally, the theme contains all parts of the clause up to and including the topic of the clause. Furthermore, the theme may be a word or a phrase as in (a):

(a) Lease payments under an operating lease shall be recognised as an expense ...

(AASB 117, para. 33).

In this case, the first phrase (in bold) functions as the theme of the first sentence. Alternatively, it may be a whole clause, as in (b):

(b) If the lease payments cannot be allocated reliably between these two elements, the entire lease is classified as a finance lease ... (AASB 117, para. 16).

It should also be noted that both extended themes in (a) and (b) are also technical and nominalised.

Text (a) above deserves further consideration. Usually a reader would expect the text to state 'Under an operating lease, lease payments shall ...' since in written texts dependent clauses or prepositional phrases typically come first. The focus of the theme however is 'lease payments'. By reordering a common pattern of English, the writer is highlighting a particular theme which also happens to be the topic of the text (leasing), but for the novice reader the usage of less typical patterns of 
English increases the technical 'feel' of the text, especially when it is used in conjunction with high Lexical Density.

The clause, in (a) above, 'Lease payments under an operating lease shall be recognised as an expense ...' is then followed by a dependent clause, '[u]nless another systematic basis is more representative of the time pattern of the user's benefit', which identifies an exception to the application of the rule. Accordingly, this text is conceptually dense not only because of the atypical theme, but because experienced English speakers may predict that the dependent clause would be the theme of the sentence and so the anticipated structure would be:

Unless another systematic basis is more representative of the time pattern of the user's benefit, lease payments under an operating lease shall be recognised as an expense on a straight-line basis over the lease term.

It was also noted that a pattern in FAS 13 is for the dependent clause to appear in a thematic position, as occurs in FAS 13, para. 36:

If the original lessee enters into a sublease/or the original lease agreement is sold or transferred by the original lessee to a third party, the original lessor shall continue to account for the lease as before.

Further instances of this include:

If at any time the lessee and lessor ... (FAS 13, para. 9)

Except as provided in paragraphs 25 and $26 \ldots$ (FAS 13, para. 11)

If the original lessee enters into a sublease ... (FAS 13, para. 36)

The dependent clause also commonly occurs as the theme in AASB 117:

Whenever necessary in order to classify and account for a lease of land and buildings, the minimum lease payments (including any lump-sum upfront payments) are allocated between the land and the buildings elements in proportion to the relative fair values of the leasehold interests in the land element and buildings element of the lease at the inception of the lease (AASB 117, para. 16).

Because the transaction between a lessor and a lessee is based on ... (AASB 117, para. 9).

If such lease transactions are not reflected ... (AASB 117, para. 21).

When a writer sets up a pattern of the construction of a text, this assists the experienced reader to recognise the structure and to predict upcoming structures to maximise reading efficiency.

However, the next example is complicated by having four clauses in the sentence, which creates high Grammatical Intricacy: 
Farrell, Farrell and Wells

If the lease payments cannot be allocated reliably between these two elements, / the entire lease is classified as a finance lease,// unless it is clear that both elements are operating leases, // in which case the entire lease is classified as an operating lease (AASB 117, para. 16).

The first two clauses are relatively simple, having the common clausal structure of a conditional clause (If ... then ...): 'If the lease payments cannot be allocated reliably between these two elements, / / [then] the entire lease is classified as a finance lease'. The third dependent clause 'unless it is clear ...' imposes limitations on the main clause and the final clause offers a solution to the situation of the third clause.

A limitation of the Grammatical Intricacy test is that it does not take into consideration other textual complexities such as the use of strings of prepositional phrases, which add another layer of density to the standards. In the text below, the prepositional phrases are bracketed thus \{\} :

Whenever necessary in order to classify and account for a lease of land and buildings,// the minimum lease payments (including any lump-sum upfront payments) are allocated between the land and the buildings elements fin proportion\} \{to the relative fair values\} \{of the leasehold interests\} \{in the land element and buildings element\} \{of the lease\} \{at the inception\} \{of the lease\} (AASB 117, para. 16).

The strings of prepositional phrases occur not only in the post-modifying position (that is after the noun group, underlined above), but also in the pre-modifying position (that is before the noun group, also underlined) as in the example below:

The present value \{of the future minimum $\}$ lease payments ... (FAS 13, para. 12).

Strings of prepositional phrases are necessary to specify conditions, exceptions, etc. and enhance the accuracy of the text. However, a string of seven prepositional phrases in the one sentence, as occurs in AASB 117, is likely to test the reading skills of even the most experienced reader. Moreover, for inexperienced readers or for readers for whom English is not their first language, the lack of familiarity with such complicated structures poses potential comprehension difficulties because extended strings are not common in most other texts nor in speech. Furthermore, in addition to decoding the Grammatical Intricacy of at least sections of the accounting standards, the reader is contending simultaneously with the complexities of Lexical Density as discussed above.

Lexical Density occurs typically when there is a high proportion of technical words in a text, when words are nominalised and when writers condense meanings in a clause or phrase. To compensate for Lexical Density, academic texts usually have a low Grammatical Intricacy (Halliday, 1994). However, analysing AASB 117 and FAS 13 using a Systemic Functional Grammar approach demonstrates that the writers of these standards have combined high Lexical Density with high Grammatical Intricacy. Writers usually have good reasons for structuring texts the way they do (Martin, 1992). One reason can be to incorporate complex ideas and intricate detail to ensure comprehensive coverage of the requirements. However, the experience for many students and accounting practitioners is that reading a text which 
has both Lexical Density and high Grammatical Intricacy is conceptually very challenging and may be open to misinterpretation. To competently read the standards a student or accounting professional requires a sophisticated understanding of the grammar of English to be able to accurately and meaningfully deconstruct the standards.

\section{CONCLUSION}

The main objective of this paper was to evaluate whether the language used in accounting standards constitutes a readability impediment to the harmonisation of accounting standards. The results showed that readability is an impediment as the application and enforcement of the standards upon which financial reporting is based are constrained by the ability of accountants to comprehend and consistently apply them. Evidence was provided across a range of tests of readability (Flesch Readability Ease Index, Flesch-Kincaid Grade Level Index, Lexical Density and Grammatical Intricacy) that the language in the standards did not score well for readability. Consequently, the readability of text in accounting standards is compromised. As a secondary issue, there was no evidence of so-called 'rules-based' regulations having better readability scores than 'principles-based' ones.

It is acknowledged that not all paragraphs were difficult to read. However, there were many paragraphs that were beyond the abilities of a first degree university/ college undergraduate at an educational grade level of around 16 to 18 (US educational system). Moreover, the easier paragraphs for readability do not alleviate the challenge for the reader who has to handle all the paragraphs in a standard as a continuum.

A limitation of this study is that it focussed exclusively on the construction of the texts. The concepts expressed in the texts were not analysed, nor could they be with the tests used. Expressions of ideas, processes and outcomes are complex not just because readability qualities create difficulties for readers. The full comprehension of standards involves much more. So solving the readability obstacles merely by using shorter sentences and fewer syllables in words, and by reducing Lexical Density and Grammatical Intricacy, will not necessarily lead to more comprehensible standards. A further limitation is that the paper focused specifically on US and international/Australian accounting standards dealing with one issue (leasing). However, the other 46 AASB standards were also assessed for readability and, on average, the Reading Ease and Grade Level scores of the other 46 AASB standards are significantly more demanding than even AASB 117.

The great challenge this paper identifies for regulators when developing regulations is to use readily understood ideas expressed in plain English. The current version of the IASB accounting standards, if judged by the analyses of the standard reported in this paper, require an exceptionally high level of education to read them accurately and comprehensively. The standard developed by the FASB is no better. The position is understated by the analyses of AASB 117. The results section reports that AASB 117 has significantly easier readability scores than all the other AASB standards on average. For those readers who converse in a diversity of non-English 
Farrell, Farrell and Wells

first languages in a world of ever-increasing globalisation, the IASB-based standards require skills in reading English at levels not achieved by a majority of fluent English speakers. This is a problem for students, practitioners and regulators.

Other readability research suggests that introductory textbooks for US post-secondary education in accounting to be around Grades 12-13 (Plucinski, Olsavsky and Hall, 2009). Why is it acceptable to have standards with paragraphs exceeding Grade 20 in the face of US research that identifies a pronounced gap between readability grades reached at high school and required at university (Williamson, 2008)?

The chairman of the IASB comments that:

This is probably the standard-setters' last chance to move the clock back to try to write shorter, less complex standards, to remove the cottage industry of the expert and return accounting to the profession. We have to move away from the position where only the technical partner understands (or thinks he or she understands) the standards. Accounting is not rocket science - we have to try to write standards for the bulk of the profession. The IASB is trying to do this ... (Tweedie, 2007, p. 8)

This paper suggests that if the road to effective standards that are comprehended by 'the bulk of the profession' and not just 'the technical partner', is to provide 'shorter, less complex standards', then the journey's end is far off indeed and the Tweedie benchmark is quite a way away. Indeed, a need for a much more intense language reform is indicated. It is not accounting but the reading of accounting standards that is the rocket science.

\section{ENDNOTES}

1 In Australia, this is achieved by the reissue by the Australian Accounting Standards Board of the relevant regulation issued by the International Accounting Standards Board.

2 Other potential factors impacting harmonisation include differing degrees of enforcement of harmonised accounting standards at the national level and the variations possible in their auditing process (dissimilarity of auditing standards or differences in interpretation and enforcement of harmonised auditing standards where used). These are beyond the scope of this paper.

3 The FASB authors standards of financial accounting that regulate the preparation of financial reports by nongovernmental organisations in the US. These standards are recognised and enforced by that country's statutory regulator of securities exchanges, the Securities and Exchange Commission (SEC).

4 In the US, these warnings are given before interrogation by police to people taken into custody. The warnings are a result of a leading decision by the US Supreme Court (Miranda v Arizona, 1966) that incriminatory statements will only be admissible in a trial if the prosecution proves the defendant was informed of the right to a lawyer before and during interrogation and was informed of the right not to self-incriminate, and the prosecution also proves that the defendant understood these rights but voluntarily waived them.

5 The literature contains numerous criticisms of the many readability tests (Zakaluk and Samuels, 1988; Davies, 1979; Woods et al. 1998). Other criticisms are listed by Woods et al. (1998). That paper also lists authors presenting criticisms. Despite all the possible shortcomings of the Readability Ease and Grade Level Indices, there are many authors who subscribe to the tests' robustness over many years, many papers that validate the tests as legitimate and countless researchers who have applied the tests to a vast array of publications (for extensive coverage see DuBay, 2004).

6 This would not be the case if the focus was on regulations concerned with financial instruments.

7 The sections are referred to as paragraphs in the standards although they do not comply with the grammatical meaning of paragraphs as generally understood. 
This is demonstrated through the work of Peter Fries, US (1970s-present); Norman Fairclough, UK (1980spresent); and, in Australia, Michael Halliday (1960s-present), Jim Martin (1980s-present) and Suzanne Eggins (1980s-present) among others.

9 Two of the paragraphs had Readability Ease scores so low they were off the scale (the formula gave negative results).

10 The Readability Ease Indices for five paragraphs were off the scale (a negative result from the formula).

11 Headings and information and guidance paragraphs from number 52 onwards were excluded.

12 Paragraphs 1-51, excluding headings and other items as described in the research design section.

13 The original problem was likely a historical consequence of paying lawyers 'a penny a word', together with their practice of ignoring punctuation in the interpretation of documents.

\section{REFERENCES}

Armstrong, C.S., Barth, M.E., Jagolinzer, A.D. and Riedl, E.J. (2007). Market Reaction to the Adoption of IFRS in Europe, Accounting Review, available from: <http://ssrn.com/ abstract $=903429>$, accessed 22 May 2008.

Barth, M., Landsman, W. and Lang, M. (2008). International Accounting Standards and Accounting Quality, Journal of Accounting Research, Vol. 46, No. 3, pp. 467-498.

Barth, M.E., Landsman, W.R., Lang, M.H. and Williams C.D. (2010). Are International Accounting Standards-Based and US GAAP-Based Accounting Amounts Comparable?, working paper no. 78, Rock Center for Corporate Governance at Stanford University, available from: <http:/ / ssrn.com/abstract=1585404>, accessed 3 March 2011.

Beattie, V., McInnes, B. and Fearnley, S. (2004). A Methodology for Analysing and Evaluating Narratives in Annual Reports: A Comprehensive Descriptive Profile and Metrics for Disclosure Quality Attributes, Accounting Forum, Vol. 28, No. 3, pp. 205-236.

Benston, G.J., Bromwich, M. and Wagenhofer, A. (2006). Principles- versus Rules-Based Accounting Standards: The FASB's Standard Setting Strategy, Abacus, Vol. 42, No. 2, pp. 165-188.

Callao, S., Jarne, J. and Lainez, J. (2007). Adoption of IFRS in Spain: Effect on the Comparability and Relevance of Financial Reporting, Journal of International Accounting, Auditing and Taxation, Vol. 16, No. 2, pp. 148-178.

Clatworthy, M. and Jones, M. (2001). The Effect of Thematic Structure on the Variability of Annual Report Readability, Accounting, Auditing \& Accountability Journal, Vol. 14, No. 3, pp. 311-326.

Cormier, D., Demaria, S., Lapointe-Antunes, P. and Teller, R. (2009). First-Time Adoption of IFRS, Managerial Incentives, and Value-Relevance: Some French Evidence, Journal of International Accounting Research, Vol. 8, No. 2, pp. 1-22.

Courtis, J. (1998). Annual Report Readability Variability: Tests of the Obfuscation Hypothesis, Accounting, Auditing \& Accountability Journal, Vol. 11, No. 4, pp. 459-471.

Dale, E. and Chall, J.S. (1948). A Formula for Predicting Readability, Educational Research Bulletin, Vol. 27, No. 1, pp. 11-28.

Davidson, R. (2005). Analysis of the Complexity of Writing Used in Accounting Textbooks over the Past 100 Years, Accounting Education: An International Journal, Vol. 14, No. 1, pp. 53-74.

Davies, P. (1979). Cloze Tests, in M. Raggett, C. Tutt and P. Raggett (eds.), Assessment and Testing of Reading: Problems and Practices, London: Ward Lock Educational.

DuBay, W. (2004). The Principles of Readability, Impact Information, available from: <http:// www.impact-information.com/impactinfo/readability02.pdf $>$, accessed 20 December 2007. 
Farrell, Farrell and Wells

Eggins, S. (2004). An Introduction to Systemic Functional Linguistics, second edition, New York, NY: Continuum.

Financial Accounting Standards Board and the International Accounting Standards Board (2002). Norwalk Agreement, available from: <http://www.fasb.org/news/memorandum. pdf $>$, accessed 22 May 2008.

Financial Reporting Council (2002). Adoption of International Accounting Standards by 2005, Bulletin, 2002/4, 3 July 2002, available from: <http:/ / www.frc.gov.au/bulletins/2002/04. asp>, accessed 20 December 2007.

Flesch, R. (1950). Measuring the Level of Abstraction, Journal of Applied Psychology, Vol. 34, No. 6, pp. 384-390.

Fung, M., Willer, B., Moreland, D. and Leddy, J. (2006). A Proposal for an Evidenced-Based Emergency Department Discharge Form for Mild Traumatic Brain Injury, Brain Surgery, Vol. 20, No. 9, pp. 889-894.

Gilliland, J. (1972). Readability, London: University of London Press for the United Kingdom Reading Association.

Goodhue, R. and Hoffmann, S. (2006). Reading the Fine Print in Agricultural Contracts: Conventional Contract Clauses, Risks and Returns, American Journal of Agricultural Economics, Vol. 88, No. 5, pp. 1237-1243.

Gunning, R. (1952). The Technique of Clear Writing, New York, NY: McGraw-Hill.

Hagge, J. and Kostelnick, C. (1989). Linguistic Politeness in Professional Prose: A Discourse Analysis of Auditors' Suggestion Letters, with Implications for Business Communication Pedagogy, Written Communication, Vol. 6, No. 3, pp. 312-339.

Halliday, M.A.K. (1994). An Introduction to Functional Grammar, second edition, London: Edward Arnold.

Harvey, V. (2006). Variables Affecting the Clarity of Psychological Reports, Journal of Clinical Psychology, Vol. 62, No. 1, pp. 5-18.

Harvey, H. and Fleming, P. (2003). The Readability and Audience Acceptance of Printed Health Promotion Materials Used by Environmental Health Departments, Journal of Environmental Health, Vol. 65, No. 6, pp. 22-28.

Heffes, E. and Graziano, C. (2007). Accounting without Borders: Has Its Time Come?, Financial Executive, Vol. 23, No. 7, pp. 22-26.

Heilke, T., Joslyn, M. and Aguado, A. (2003). The Changing Readability of Introductory Political Science Textbooks: A Case Study of Burns and Peltason: 'Government by the People', PS: Political Science and Politics, Vol. 36, No. 2, pp. 229-232.

International Accounting Standards Committee (2007). IASC Foundation Constitution, International Accounting Standards Committee, available from: <http://www.iasb.org/NR/ rdonlyres/1904AEEE-3554-49C6-BD96-A4611A6964BE/0/IASCFoundationConstitution 2.pdf $>$, accessed 20 December 2008.

Jeanjean, T., Lesage, C. and Stolowy, H. (2010). Why Do You Speak English (in your Annual Report)?, The International Journal of Accounting, Vol. 45, No. 2, pp. 200-223.

Kerr, D. (2007). Information in Diabetes Care: Is there a Need to Dumb Down even More?, Diabetic Medicine, Vol. 24, No. 5, pp. 561-563.

MacDonald, L.A. (2002). Principles-Based Approach to Standard Setting, The FASB Report, 27 November 2002, available from: <http://www.fasb.org/project/principles-based_ approach.shtml>, accessed 20 December 2007.

Maines, L., Battov, E., Fairfield, P., Hirst, D.E., Iannaconi, T., Mallett, R., Schrand, C., Skinner, D. and Vincent L. (2003). Evaluating Concepts-Based vs. Rules-Based Approaches to Standard Setting, Accounting Horizons, Vol. 7, No. 1, pp. 73-89.

Martin, J.R. (1992). English Text: System and Structure, Philadelphia, PA: John Benjamins Publishing Company. 
McLellan, T. and Dobinson, G. (2004). Tertiary Education of Journalists and the Readability of Australian Newspapers, Australian Journalism Review, Vol. 26, No. 1, pp. 155-174.

Miranda v Arizona (1966). 384 US 436 (1966), available from: <http://supreme.justia.com/ us/384/436/case.html>, accessed 7 March 2011.

Nelson, M. (2003). Behavioral Evidence on the Effects of Principles- and Rules-Based Standards, Accounting Horizons, Vol. 17, No. 1, pp. 91-104.

Nelson, M.W., Elliott, J.A. and Tarpley, R.L. (2002). Evidence from Auditors about Managers' and Auditors' Earnings Management Decisions, Accounting Review, Vol. 77 (Supplement), pp. 175-202.

Paananen, M. and Lin, H. (2009). The Development of Accounting Quality of IAS and IFRS over Time: The Case of Germany, Journal of International Accounting Research, Vol. 8, No. 1, pp. 31-55.

Plucinski, K., Olsavsky, J. and Hall, L. (2009). Readability of Introductory Financial and Managerial Accounting Textbooks, Academy of Educational Leadership Journal, Vol. 13, No. 4, pp. 119-127.

Richardson, G. and Smith, D. (2002). The Readability of Australia's Goods and Services Tax Legislation: An Empirical Investigation, Federal Law Review, Vol. 30, No. 3, pp. 475-506.

Rogers, R., Harrison, K., Shuman, D., Sewell, K. and Hazlewood, L. (2007). An Analysis of Miranda Warnings and Waivers: Comprehension and Coverage, Law and Human Behavior, Vol. 31, No. 2, pp. 177-192.

Rutherford, B. (2003). Obfuscation, Textual Complexity and the Role of Regulated Narrative Accounting Disclosure in Corporate Governance, Journal of Management and Governance, Vol. 7, No. 2, pp. 187-210.

Schipper, K. (2003). Principles-Based Accounting Standards, Accounting Horizons, Vol. 17, No. 1, pp. 61-72.

Smith, M. and Taffler, R. (1992). Readability and Understandability: Different Measures of the Textual Complexity of Accounting Narrative, Accounting, Auditing \& Accountability Journal, Vol. 5, No. 4, pp. 84-98.

Stalebrink, O. and Sacco, J. (2007). Rationalization of Financial Statement Fraud in Government: An Austrian Perspective, Critical Perspectives on Accounting, Vol. 18, No. 4, pp. 489-507.

Stockmeyer, N. (2009). Using Microsoft Word's Readability Program, Michigan Bar Journal, Vol. 88, No. 1, pp. 46-47.

Sydserff, R. and Weetman, P. (1999). A Texture Index for Evaluating Accounting Narratives, Accounting, Auditing \& Accountability Journal, Vol. 12, No. 4, pp. 459-488.

Tweedie, D. (2007). Can Global Standards Be Principle Based?, Journal of Applied Research in Accounting and Finance, Vol. 2, No. 1, pp. 3-8.

Wallis, C. (2005). Why Are Rulings so Difficult and Time Consuming to Read?, Taxation in Australia, Vol. 39, No. 10, pp. 537-543.

Williams-Deane, M. and Potter, L. (1992). Current Oral Contraceptive Use Instructions: An Analysis of Patient Package Inserts, Family Planning Perspectives, Vol. 24, No. 3, pp. 111-115.

Williamson, G. (2008). A Text Readability Continuum for Postsecondary Readiness, Journal of Advanced Academics, Vol. 19, No. 4, pp. 602-629.

Woods, B., Moscardo, G. and Greenwood, T. (1998). A Critical Review of Readability and Comprehensibility Tests, Journal of Tourism Studies, Vol. 9, No. 2, pp. 49-61.

Zakaluk, B.L. and Samuels, S.J. (1988). Readability: Its Past, Present, and Future, Newark, DE: International Reading Association. 